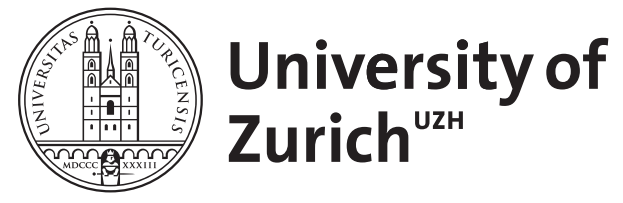

\title{
The ethics of evidence
}

Biller-Andorno, Nikola ; Wild, Verina

\begin{abstract}
Basing normative judgment and policy on a rich empirical account of the issue at hand is usually a good idea. But doing nothing and awaiting further evidence can sometimes itself be bad judgment. This is the case with female genital cutting. We already know what is needed to define the conditions under which female genital cutting is morally unacceptable and that we can legitimately act on this knowledge.
\end{abstract}

DOI: https://doi.org/10.1002/hast.92

Posted at the Zurich Open Repository and Archive, University of Zurich ZORA URL: https://doi.org/10.5167/uzh-69880

Journal Article

Published Version

Originally published at:

Biller-Andorno, Nikola; Wild, Verina (2012). The ethics of evidence. Hastings Center Report, 42(6):2930.

DOI: https://doi.org/10.1002/hast.92 
for sound reasons. Also open to question is the voluntariness of adult women's embrace of female genital cutting when they are told that they are not marriageable unless they are cut, or that their genitalia are ugly.

Finally, what are we to make of the statement that "Female genital surgery in Africa is typically controlled and managed by women?" The United Nations interagency statement has this explanation: "In many societies, older women who have themselves been mutilated often become gatekeepers of the practice, seeing it as essential to the identity of women and girls. This is probably one reason why women, and more often older women, are more likely to support the practice, and tend to see efforts to combat the practice as an attack on their identity and culture." 4

Women may be wronged, in addition to being harmed, when they are subjected to the traditional custom of female genital cutting. Respect for cultural traditions is a cardinal rule for anthropologists, but such traditions must stand up to ethical scrutiny.

1. International Federation of Gynecology and Obstetrics, "FIGO Supports 2012's International Day of Zero Tolerance to Female Genital Mutilation," February 6, 2012, http://www.figo. org/files/figo-corp/International\%20Day\%20of\%20Zero\%20Tolerance $\% 20$ to $\% 20$ Female $\% 20$ Genital $\% 20$ Mutilation $\% 20-\% 20$ 2012.pdf.

2. A. Elnashar and R. Abdelhady, "The Impact of Female Genital Cutting on Health of Newly Married Women," International Journal of Gynaecology and Obstetrics 97, no. 3 (2007): 238-44.

3. UNAIDS, UNDP, UNECA, UNESCO, UNFPA, UNHCHR, UNHCR, UNICEF, UNIFEM, WHO, "Eliminating Female Genital Mutilation: An Interagency Statement" (Geneva, Switzerland: World Health Organization, 2008), http://www. un.org/womenwatch/daw/csw/csw52/statements_missions/Interagency_Statement_on_Eliminating_FGM.pdf.

4. Ibid.

\section{The Ethics of Evidence}

by NIKOLA BILLER-ANDORNO AND

VERINA WILD

B asing normative judgment and policy on a rich empirical account of the issue at hand is usually a good idea. But doing nothing and awaiting further evidence can sometimes itself be bad judgment. This is the case with female genital cutting.

It is plainly wrong to submit individuals who are not in a position to make a reasonably free and informed decision to an intervention that does not carry any medical benefit but comes with a significant potential for harm. Our claim is that we already know what is needed to define the conditions under which female genital cutting is morally unacceptable and that we can legitimately act on this knowledge. Further data might help us, however, to refine our strategies to combat such practices. So what evidence should we seek?

Certainly, the debate could be enhanced by the narrative accounts of women who have had firsthand experiences of some form with the practice. But even if some of these stories were positive, this would not mean that

Nikola Biller-Andorno and Verina Wild, "The Ethics of Evidence," Hastings Center Report 42, no. 6 (2012): 29-30. DOI: 10.1002/hast.92 there are moral or policy reasons to tolerate female genital cutting. In earlier times, some societies used to accept crippling girls' feet to make them appear small and "beautiful." Still, our moral rejection of this custom would not change if somebody happened to speak up in favor of it today.

Do we need further evidence about the psychological and physical consequences of the procedure before we can define our moral position? There is no plausibility for any immediate health benefit, but a number of obvious reasons to expect that the well-being of many who might undergo the procedure will be seriously impaired. One could not imagine, say, a randomized, controlled trialparticularly one that involved children-that assumed some sort of equipoise regarding health status with and without the intervention. Similarly, it is hard to imagine that long-term cohort studies, following children from the intervention on through their adolescence and early adult years, would pass an ethics review committee in the post-Tuskegee era. Carrying out such studies would not reflect a neutral, "unbiased" moral stance but would in fact mean condoning the practice, at least for the time being, rendering the researcher an accomplice.

Are we in need of evidence for a special link between genital surgery and patriarchy before we can commit to a moral position against it? We certainly want to better understand the origins and maintaining factors of this 
tradition. However, it seems naive to assume that "sealing" or "cleaning" girls or young women "before use" did not have to do with domination and commodification. If, on the other hand, female genital cutting was indeed about standards of beauty, then it would be at least as appalling that parents would so bluntly violate their little girls' rights to physical integrity just for aesthetic reasons.

The fact that women organize and perform genital cuttings does nothing to prove that they are doing so as the result of an autonomous choice. Rather, it calls into question whether these women are so entrenched in local customs and social structure that deviating from it is not an option. Likewise, we cannot assume that those undergoing genital cutting-especially children-have given anything close to a meaningful informed consent. Even a teenage girl or young woman may not see herself as someone having a choice, as being able to say "no," which would be a minimum moral requirement for an invasive procedure that has no medical indication whatsoever, particularly if carried out in a regulated, clinical environment. Exploring decision-making processes and how autonomy can be enhanced in such contexts would, in fact, be an important object of study.
In these and similar debates_-about organ trading, for instance-the charge of cultural supremacy is used as a killer argument: "You are an outsider and have no right to judge what we are doing." However, invoking universally shared values has nothing to do with cultural imperialism. We globally share the view that certain practices may be banned for the sake of protecting the well-being of those who would otherwise be at risk of harm, although in many cases there are controversial debates about what constitutes the most appropriate policy response. Aesthetic genital surgery carried out in Western countries is also the subject of ongoing criticism and scrutiny, which has led to a call for particularly high-quality standards for these procedures, including a careful investigation into whether a patient's decision for an operation was indeed informed, well considered, and voluntary.

Requiring more data before committing to a stance against clearly unacceptable forms of female genital cutting is not a proof of neutrality. It means failing to protect a very vulnerable population. Rather, data, diligence, and familiarity with local contexts are needed to define the best way to render social customs compatible with shared global norms.

\section{Using Facts to Moderate the Message}

by NAWAL M. NOUR

T he Public Policy Advisory Network on Female Genital Surgeries in Africa has written an article expressing concern about the media's inaccurate depiction of this practice and suggesting a more fact-based approach to reporting on it. The article states that women who have undergone genital cutting have rich sexual lives, rarely have health complications, and view these surgeries as aesthetic enhancements. (I cannot address their other points here for lack of space.) They believe that the media sensationalize the practice, and specifically, that the media have inaccurately covered the World Health Organization study published in the Lancet in 2006.

I applaud the network for soliciting input from various fields. I cannot agree more that some in the media have misconstrued, exaggerated, and used inflammatory

Nawal M. Nour, "Using Facts to Moderate the Message," Hastings Center Report 42, no. 6 (2012): 30-31. DOI: 10.1002/hast.93 language; words like "torture," "barbaric," and "horrific" will likely enrage readers while reinforcing discrimination against women who practice or have undergone genital cutting. The media have undeniably shaped the Western view of this tradition, and many articles might prompt a reader to ask, "How can parents do this to their daughters?" The fact that parents may do this for their daughters - to make them marriageable in cultures where marriage is required not only for social acceptance, but for survival — can be missed. More efforts should be made to promote a deeper understanding of the complexity of the practice, including what drives and perpetuates itand the media could help.

Speaking as both an African woman and an obstetrician-gynecologist, I hope that this practice ends during my lifetime. However, the impetus to abandon female genital cutting must come from within each community; a ban on it cannot be imposed by outsiders. In my work at the African Women's Health Center at Brigham and Women's Hospital, I have seen both major and minor long-term complications of the practice on women's health and in women's lives. My career has been spent 